\title{
The Counseling Techniques in Tackling the Problem of Truancy Among the Students of Uttarakhand Schools
}

\author{
Manoranjan Tripathy ${ }^{*}$ and Bisweswari Sahu²
}

${ }^{1 *}$ Assistant Professor, Department of Psychology, Dev Sanskriti Vishwavidyalaya, Haridwar, Uttarakhand, India

${ }^{2}$ Assistant Professor, Doon Group of Institutions, Rishikesh, Uttarakhand, India.

Email: manoranjanonly@gmail.com; bisweswari1978@gmai.com

*Corresponding author details: Dr. Manoranjan Tripathy, manoranjanonly@gmail.com

\begin{abstract}
The term behavioral problem' refers to a type of serious abnormality in the behavior of an individual resulting into his maladjustment with the self and the environment and proving detrimental to the welfare of his self and the society. Example of such behavior is truancy, lying, stealing; temper tantrums, drug addiction and juvenile delinquency. Truancy is a behavioral problem relates with students in school at all levels of education. The researcher carried out a theoretical work by using counseling techniques in tackling the problem of truancy in schools' of Uttarakhand, various techniques were used in resolving problem of truancy in Uttarakhand schools include Rational Emotive Behavioural Therapy (REBT) of Albert Ellis and Behavioural Modification include; modeling, assertiveness training, cognitive restructuring, behavioural modification, reinforcement both positive and negative. Effects of truancy on academic performance of the students in schools were spelt out. Various counseling implications were discussed which include; the need to form an attendance review team to catch problem of truancy as early as possible, provision of individualize support for the children in school, building a positive school culture to guide the child in school and focusing on the most essential behaviors that are noticeable in schools. Problem of truancy would definitely be solved if used all the suggested techniques and skills appropriately by a trained professional counseling.
\end{abstract}

Keywords: counseling techniques; truancy; school students

\section{INTRODUCTION}

Truancy as a behavioural problem relates with the school life of a child. A child demonstrates such a behavior problem when he willingly remains absent from the classroom or other activities of the school without bringing it to notice of his teachers, parents or school authorities. Causes of truancy lie in the factors and circumstances related to one's self and the environmental environments like one's physical and mental health, level of the physical and mental abilities, improper behavior and maltreatment received from the peers, elder students, teachers and school authorities, improper methods of teaching, lack of co- curricular activities and hobbies, indiscipline prevalent in the school, ill effects of bad company; defective home environment, difficulty in the satisfaction of the basic needs, desire and tendency to escape from work, social and emotional maladjustment, to prove superiority and courage by indulging in such negative behavior.

Remedial measures for the truant behavior involve both the preventive as well as curative measures. It can be improvised by the different type of guidance and counseling. According to (Obumneke-Okeke \& Mogbo, 2011) the importance of guidance and counseling programme in secondary schools, include bringing to the students an increased understanding of the educational, vocational and social information needed to make wise choices. In our society there are many influencing forces responsible for the gradual recognition of formal guidance to young people in various educational levels.

Counseling is said to be a helping profession which deals with the process of helping individuals to discover and develop their educational, vocational and psychological potentialities and thereby achieve an optimal level of personal happiness and social usefulness (Ipaye, 1995). It could be classified into two types which include individual counseling and group counseling. In an individual counseling, the trained counselor uses his professional skills and techniques in handling individual with a problem and how it could be solved while group counseling involves a professional trained counselor handling clients or individuals' problems with a minimum of five clients and maximum of seven but should have similar problems (Rutan \& Alonso, 1982). 
Techniques are the major instruments used by counselors during counseling session either in an individual or group and that is why counseling is differed from advice giving (van Rooyen, Durrheim \& Lindegger, 2011). Truancy is the action of staying from school without good reason or without permission (Attwood \& Croll, 2006). Other names for truancy are school refusals or school phobia. At the community level, truancy is associated with higher rates of criminal activity, fewer productively contributing citizens, and higher government spending for social services (Baker, Sigmon \& Nugent, 2001). Truancy is a ubiquitous problem. However, it should not be assumed that truant youth are a homogenous group. Truants have different risk profiles based on various demographic factors. For example, older youth, minority youth, and youth from lower socioeconomic backgrounds are more likely to be truant than younger youth, youth who are White, and youth from more affluent backgrounds (Henry, 2007; Henry \& Huizinga, 2007; MacGillivary \& Erickson, 2006; Vaughn et al., 2013).

Truants also have different risk profiles based on psychosocial indicators. Maynard et al., (2012, 2013) found four distinct classes of truant youth when using latent class analysis to examine heterogeneity in terms of school engagement, participation in school activities, grades, parental academic involvement, and number of days skipped. They identified an achiever class, characterized by higher levels of school engagement and participation in school activities and parental academic involvement; a moderate student class, with a higher level of school engagement, but mean levels for all other academic characteristics; an academically disengaged class, characterized by low levels of school engagement, poor grades, low participation in school activities, low levels of parental involvement; and a chronic skipper class similar to the academically disengaged class with the exception of much higher rates of skipping. The four distinct classes of truant youth were also differentially associated with sociodemographic factors and externalizing behaviors. Members in the chronically truant class were more likely to use marijuana and engage in theft, drug sales and fighting than the other classes.

\section{CAUSES OF TRUANCY}

According to Zhang, Katsiyannis, Barrett, and Wilson (2007), the causes for truancy can be positioned within four major categories. These categories include family factors, school influence, student factor and health factor;

Family Factor: Inadequate supervision on the part of child's parent, too much house chores, non-intact homes such as divorce, broken, separated, living apart could cause truancy. He further expatiated that illiteracy on the part of child's parent as a result of ignorance is another cause. The poor social economic factor on the part of the child's parent could also cause truancy and also accepted that parenting styles could also responsible for child's truancy in school. Parenting styles include; authoritarian and lazier-faire or when a child is endowed with too much freedom.

School Influence: School as one of the agencies of socialization could also responsible for truancy on the following ways; negative peer influence, un-conducive school enrolment, bullying by the child's colleagues, boredom as a result of examination failure, overpopulation of members, poor location of school, community influences and teachers' method of teaching when not enjoyable.
Student Factor: The students themselves are influenced and several factors are caused for their truancy which include; when a child is a slow learner he or she sees nothing attractive in school, emotional problem as a result of inferiority complex, lack of ambition as popularly called "No Future Ambition" (NFA), getting poor grades will discourage him or her from school and learning disabilities and difficulties would scare him or her away from school. Such a child may decide to taking of substances abuse.

Health Factor: This is another factor that responsible for truancy among students in secondary schools which include; illness, mental illness, mental retardation, attention deficit hyperactivity disorder (ADHD), emotional well-being, social well-being and post-traumatic stress disorder.

\section{EFFECTS OF TRUANCY}

Several effects of truancy have negative impact on the client which is the following;

- Low or poor academic performance in school.

- Cheating and involving in examination malpractices

- Joining of gangs/occultism

- Involvement in substance abuse

- Involvement in crime such as stealing

- Juvenile delinquency

- Isolation, he or she may prefer to be alone always

- Involvement in sexual misconduct.

- It may cause unwanted pregnancy

- It may result to school drop out

- It may result to mental illness if persisted

\section{HANDLING A CHILD WITH SCHOOL TRUANCY}

Counseling is a voluntary self-help profession and the child who needs help should contact the trained counselor in different ways. Something should necessitate counseling.

- It may be a referral from the parents or teachers of the client to see a counselor if the parent discovers that he or she needs help.

- The client may submit him or herself when he or she realizes his/her challenge and might decide to seek counselor's help.

- The counselor can notice or discover the child with the problem of truancy and decides to invite him or her for counseling.

\section{COUNSELING CLINIC}

The venue where the client and the counselor are meeting during counseling session is called counseling clinic. The setting is attractive, containing comfortable furniture, tape recorder, files and jotters, various psychological tests or inventories for collecting data of the client during counseling session.

\section{PRE-COUNSELING}

Before moving to counseling proper, there would be precounseling on the part of the counselor where he or she is expected to create a rapport and it is called rapport establishment, asking questions concerning the bio-data of the client, guaranteeing of the client's confidentiality which involves keeping secret-secret. Seeking indulgence of the client to jot down notes if needed to record the counseling session, especially for academic purpose and finally agreement on time and venue of meeting 


\section{COUNSELOR'S QUALITIES}

There are qualities that must be possessed by the counselor for an effective counseling to take place which include;

- Acceptance of the client

- Giving unconditional positive regard to the client

- Showing empathy to your client

- He must be knowledgeable and expertise since you cannot give what you don't have.

- He must also have sense of humour

\section{COUNSELING SKILLS}

Counselor must have acquired certain skills that would be of help during counseling session.

- $\quad$ Attending - paying attention to the client and couples it with active listening.

- $\quad$ Silence - allowing your client to say what he or she has in mind.

- $\quad$ Focusing - do not be diverted from the real problem and rather be focused.

- Questioning - asking your client questions to discover more facts about him or her.

- Probing - asking him or her question to say out what he or she might be reluctant to say.

- Confrontation - this is needed when the client is hiding some truth or information about him or herself.

- Reflection and paraphrasing: these are useful for more clarification during counseling.

- Effective communication - take note of the client verbal and non-verbal expression during counseling session.

\section{WAYS OF TACKLING TRUANCY}

Truancy may be handled at the initial stage in the following ways if the client problem's is discovered at early stage before it becomes a perpetual truant.

- They may form an attendance team (monitoring attendance daily).

- Be friendly with the child.

- Celebrating the successes of the truant

- Joining clubs and parties participating in sports - A truant would definitely come on the day of sport if loved sports.

- Instructing parents and guardians to engage in proper monitoring their wards.

\section{COUNSELOR'S WAY OF HANDLING TRUANCY}

Truancy can be handled by using some techniques in counseling theories to handle truancy. One of the major theories that are appropriate in dealing with truancy is Rational Emotive Behavioural Therapy (REBT) by Ellis (1995). Ellis beliefs that people condition themselves to feel disturbed and none is responsible for his being disturbed, the erroneous beliefs that someone is responsible for what the client is passing through is not true but he or she is the real cause of his/her problem. The erroneous belief would now be disputed.

Ellis originates several techniques in his theories that could help in resolving truancy which include; modeling, assertiveness training, and cognitive - restructuring.
Modeling: The truant should try to emulate and imitate those students who are punctual in school and copy them so as to be effective and performing well in his academic.

Assertiveness training: The truant should try to be assertive, having it in his/her mind that he/she could do better, let he or she be repeating it several times that "I will do better", "I will stop absenteeism" by saying these, he/she would work towards achieving it. This is called "record broken".

Cognitive-Restructuring: Here, the truant would erase the erroneous belief that someone is responsible for his truancy such as poor home, parental ignoring, lack of funds etc. but should try to turn a new leaf that he is the cause of the problem he/she is passing through by disputing the irrational thinking and erroneous beliefs.

Social Skill: Can also be used in handling truancy here the student would try to cope with stigmatization that resulted from truancy.

Behavioural Modification: It is a maladaptive behaviour. Behaviour modification involves the reducing or eliminating evasive responses, undesirable or unhealthy behaviour and learning or increasing pleasant responses or desirable and healthy.

Other counseling techniques are:

- Reinforcement

- Positive reinforcement

- Negative reinforcement

- Schedule of reinforcement

- Contingency contract

- Token economy

Reinforcement is a strong technique that will strengthen in organism future behaviour whenever that behaviour is preceded by a specific antecedent stimulus. There are two types of reinforcement namely positive and negative reinforcement.

For positive reinforcement, a reward is offered on expression of the wanted behaviour. Truancy is corrected when a child is encouraged to attend and constantly present in school for a period of week, the counselor would assure him or her the need to reward him/her so as to repeat the same behaviour. The moment is being rewarded, he/she will be repeating the expected behaviour (Schultz, 2015). The positive reinforces then provide a desirable stimulus.

The negative reinforcement is characterized by taking away an undesirable stimulus. A perpetual truant may not allow or remove the pleasure he or she enjoys in absenting him/her from school (Schultz, 2015). Contingency contract is an if-then agreement that states which actions under certain conditions will result in specific outcome (Bazerman\& Gillespie, 1999).

This is an agreement between a truant and the counselor, where both of them would sign agreement on the part that the truant would be rewarded if stood to the agreement of attending school regularly, he or she will be rewarded. This is not automatic or permanent, if violated the contract, then they may break it. 
Token economy is a behaviour therapy, a programme, sometimes conducted in an institutional setting like hospital, classroom and churches. Here the desired behaviour is reinforced by offering tokens that can exchanged for special foods, television time, passes or other rewards (Jackson \& Hackenberg, 1996). It is commonly used and has been successfully modeled with pigeons in laboratory setting. The counselor may decide to reward the child if attended school to serve as reinforcement to repeat the same behaviour.

\section{COUNSELING IMPLICATIONS IN TACKLING TRUANCY}

- There is need to form an attendance review team to catch problem of truancy as early as possible.

- $\quad$ There is need to provide individualize support for the children in schools.

- There is need to build a positive school culture to guide the child in school.

- There is also need to focus on the most essential behaviors that are noticeable in schools.

\section{CONCLUSION}

Truancy is one of the behaviour that causes examination failure in our schools. This behaviour is very perpetual in our schools and there would be need to curb it. Many of the students that are physically and mentally sound cannot attain or achieve academic success due to truancy.

If truancy is dealt with at early stage it would not harm the future of the child. Various skills and techniques can be employed in tackling the problem of truancy among students in Uttarakhand schools if well handled by a professional trained counselor.

One can use more than one technique to achieve the desired goal which is behaviour modification. However, this goal cannot be achieved in a session, it might take some counseling sessions, weeks or months depending on the gravity of the maladaptive behaviour (in this case truancy needs to be dealt with since it can ruin the career of a students in the future).

\section{REFERENCES:}

[1] Attwood, G., \& Croll, P. (2006). Truancy in secondary school pupils: Prevalence, trajectories and pupil perspectives. Research papers in education, 21(4), 467-484.

[2] Baker, M. L., Sigmon, J. N., \& Nugent, M. E. (2001). Truancy Reduction: Keeping Students in School. Juvenile Justice Bulletin.

[3] Bazerman, M. H., \& Gillespie, J. J. (1999). Betting on the future: The virtues of contingent contracts. Harvard Business Review, 77, 155-162.

[4] Ellis, A. (1995). Changing rational-emotive therapy (RET) to rational emotive behavior therapy (REBT). Journal of Rational-Emotive and Cognitive-Behavior Therapy, 13(2), 85-89.

[5] Henry, K. L. (2007). Who's skipping school: Characteristics of truants in 8th and 10th grade. Journal of school health, 77(1), 29-35.

[6] Henry, K. L., \& Huizinga, D. H. (2007). School-related risk and protective factors associated with truancy among urban youth placed at risk. The journal of primary prevention, 28(6), 505-519.

[7] Ipaye, B. (1995). Guidance and Counseling in Nigerian Schools. Ilorin: Chayoobi Printers \& Publishers.
[8] Jackson, K., \& Hackenberg, T. D. (1996). Token reinforcement, choice, and self-control in pigeons. Journal of the Experimental Analysis of Behavior, 66(1), 29-49.

[9] MacGillivary, H., \& Erickson, G. (2006). Truancy in Denver: Prevalence, effects and interventions. Denver, CO: National Center for School Engagement.

[10] Maynard, B. R., McCrea, K. T., Pigott, T. D., \& Kelly, M. S. (2012). Indicated truancy interventions: Effects on school attendance among chronic truant students. Campbell Systematic Reviews, 8(1), 1-84.

[11] Maynard, B. R., McCrea, K. T., Pigott, T. D., \& Kelly, M. S. (2013). Indicated truancy interventions for chronic truant students: A Campbell systematic review. Research on Social Work Practice, 23(1), 5-21.

[12] Maynard, B. R., Salas-Wright, C. P., Vaughn, M. G., \& Peters, K. E. (2012). Who are truant youth? Examining distinctive profiles of truant youth using latent profile analysis. Journal of Youth and Adolescence, 41(12), 1671-1684.

[13] Obumneke-Okeke, I. M., \& Mogbo, I. N. (2011). Implementation of guidance and counseling services in Nigerian schools. Journal of Emerging Trends in Educational Research and Policy Studies, 2(5), 361-364.

[14] Rutan, J. S., \& Alonso, A. (1982). Group therapy, individual therapy, or both?. International Journal of Group Psychotherapy, 32(3), 267-282.

[15] Schultz, W. (2015). Neuronal reward and decision signals: from theories to data. Physiological reviews, 95(3), 853-951.

[16] Van Rooyen, H., Durrheim, K., \& Lindegger, G. (2011). Advice-giving difficulties in voluntary counselling and testing: a distinctly moral activity. AIDS care, 23(3), 281-286.

[17] Vaughn, M. G., Maynard, B. R., Salas-Wright, C. P., Perron, B. E., \& Abdon, A. (2013). Prevalence and correlates of truancy in the US: Results from a national sample. Journal of adolescence, 36(4), 767-776.

[18] Zhang, D., Katsiyannis, A., \& Barrett, D., Wilson, V. (2007, August). Truancy Offenders in the Juvenile Justice System. Remedial and Special Education, 28, 244-256. 